Short communication

\title{
A pathological scapula in a mosasaur from the upper Maastrichtian of Antarctica: Evidence of infectious arthritis and spondyloarthropathy
}

\author{
Marianella Talevi a, *, Bruce Rothschild b, c, Marta Fernández ${ }^{\text {d }}$, Marcelo Reguero e, f, \\ Matías Mitidieri ${ }^{\mathrm{g}}$ \\ a Instituto de Investigación en Paleobiología y Geología, CONICET-Universidad Nacional de Río Negro, Av. Roca 1242, R8332EXZ, General Roca, Río Negro, \\ Argentina \\ ${ }^{\mathrm{b}}$ The Carnegie Museum, 4400 Forbes Ave, Pittsburgh, PA, 15232, USA \\ ${ }^{c}$ Indiana University Ball Memorial Hospital, 2401 W University Drive, Muncie, IN 47303, USA \\ d División Paleontología de Vertebrados, CONICET-Museo de La Plata, Paseo del Bosque s/n, B1900FWA, La Plata, Argentina \\ e Instituto Antártico Argentino, 25 de Mayo 1151 CP 1650, San Martín, Capital Federal, Argentina \\ f División Paleontología de Vertebrados, Museo de La Plata, Paseo del Bosque s/n, B1900FWA, La Plata, Argentina \\ ${ }^{g}$ Universidad Nacional de Río Negro, EEUU 750, R8332EXZ, General Roca, Río Negro, Argentina
}

\section{A R T I C L E I N F O}

Article history:

Received 13 February 2019

Received in revised form 20 March 2019

Accepted in revised form 25 March 2019 Available online 29 March 2019

\section{Keywords:}

Pathology

Marine reptile

Cretaceous

Antarctica

\begin{abstract}
A B S T R A C T
We describe infectious arthritis and spondyloarthropathy in a juvenile mosasaur recovered from the upper Maastrichtian of Antarctica, representing the first report of a skeletal pathology of a mosasaur from the southern hemisphere. Macroscopic examination of the scapula revealed a remodelled, deeply excavated and expanded gleno-humeral joint with adjacent linear disruption. X-ray examination revealed a deep excavation expanding the glenoid fossa, with disorganized subchondral bone and a focal spherical defect. The individual did not continue to grow for a long time after the appearance of the lesion. Although not directly related to the mosasaur death, this condition may have contributed to the demise of the animal by reducing its effectiveness at obtaining food or increasing susceptibility to fatal disease, additional injury, or even predation.
\end{abstract}

๑) 2019 Elsevier Ltd. All rights reserved.

\section{Introduction}

Paleopathological studies have been used to understand the history of injuries and diseases in extinct forms (Rothschild and Martin, 2006). These analyses also allow, by means of exploration of types of skeletal damages, their frequencies and putative underlying causes and to infer paleoecological and behavioural aspects of extinct populations (Moodie, 1918; Rothschild and Martin, 2006; Pardo Perez et al., 2018b). Paleopathologies in fossil vertebrates are usually identified only if they damage or alter the skeleton but see Rothschild and Depalma (2013). When damage is the result of a traumatic injury (e.g., fractures) the bones develop callus during healing. Infectious diseases may develop de novo or after trauma (Lingham-Soliar, 2004; Rothschild et al., 2012a).

\footnotetext{
* Corresponding author.

E-mail addresses: mtalevi@unrn.edu.ar (M. Talevi), spondylair@gmail.com (B. Rothschild), martafer@fcnym.unlp.edu.ar (M. Fernández), regui@fcnym.unlp. edu.ar (M. Reguero), matiasmitidieri@yahoo.com.ar (M. Mitidieri).
}

Alternatively, bone pathologies may be the result of other factors that cause mechanical problems or physiological stress (Kompanje, 1999; Rothschild and Martin, 2006; Cooper and Dawson, 2009). Examples of paleopathologies have been widely observed and recognized among fossil vertebrates, including dinosaurs and various marine reptiles (Rothschild and Martin, 1993; Bishop et al., 2015). In the case of the latter, recognition and study of certain bone pathologies linked to the aquatic environment have allowed knowing precise aspects of the physiology and paleoecology of some groups of marine reptiles (Motani et al., 1999; Rothschils and Storrs, 2003). Ichthyosaurs, plesiosaurs and mosasaurs (Rothschild and Martin, 1987; Motani et al., 1999; Rothschild and Storrs, 2003; Beatty and Rothschild, 2008; Rothschild et al., 2012a,b; Pardo Pérez et al., 2018a) developed avascular necrosis, indicating that, under certain circumstances, these groups suffered from "Decompression Syndrome", as a result of the development of diving habits. Infections are a well-recognized complication of injuries, as noted in dinosaurs (e.g., the Tyrannosaurus Sue) and marine reptiles (e.g., Mosasaurus), with joint infections specifically noted in shoulders of pliosaurs (Tanke and Rothschild, 2002; Rothschild et al., 2012a,b, 
2018). Spondyloarthropathy has been previously recognized as pan-phylogenetic in mammals (affecting $20 \%$ of some species) and as isolated phenomenon in Dimetrodon, Diadectes, Ctenorhachis, mosasaurs (e.g., Mosasaurus), hadrosaurs, ceratopsia (Rothschild and Martin, 2006; Rothschild et al., 2012a,b). It is predominantly vertebral in distribution, although peripheral joints have sometimes been affected.

Northern Patagonia and the Antarctic Peninsula have rich records of Upper Cretaceous (Campanian and Maastrichtian) reptiles. Although paleopathology studies represent a vast field of novel information in etiological terms and insight to resulting limitations affecting behaviour and provides a glimpse of the possible survival strategies under which these reptiles lived (Rothschild et al., 2018), palaeopathologies have not been previously reported from the abundant and diverse marine reptile assemblages from Patagonia and Antarctica.

In this contribution we describe infectious arthritis in a juvenile mosasaur recovered from the upper Maastrichtian of Antarctica, representing the first report of a skeletal pathology of a mosasaur from the southern hemisphere.

\section{Geological background}

The mosasaur remains studied here consist of a scapula, collected in 1987 during a summer fieldtrip in the Antarctic Peninsula carried out by the staff of the Division Paleontologia de Vertebrados (Museo de La Plata, Argentina) and the Instituto Antártico Argentino. The fossil was recovered from the López de Bertodano Formation outcrops at Marambio Island (Seymour Island), Antarctica (O'Gorman et al., 2017: fig. 1). This formation was originally divided into ten units (Units $1-10$ ), but recently Unit 1 has been considered to be part of the Haslum Crag Sandstone Member of the Snow Hill Island Formation (Olivero and Malumián, 2008; Olivero, 2012). The lower units, from 2 to 6, are informally named 'Rotularia Units', while the upper units, from 7 to 10 are named 'Molluscan Units'). The 'Molluscan Units' are highly fossiliferous, especially Units 9 and 10 , which straddle the $\mathrm{K}-\mathrm{Pg}$ boundary (Elliot et al., 1994; Macellari, 1998; Zinsmeister, 1998). Depending on the base of section used and the particular study, this interval represents about 1100 stratigraphic meters, with the Rotularia Units comprising the lower $\sim 600 \mathrm{~m}$, and the iridium anomaly representing the K-Pg boundary located at the lithologically defined Unit 9-Unit 10 boundary (Elliot et al., 1994). The specimen described in this contribution was collected between Units 8 and 9 . These units consist of massive mudstones and silty, very fine-grained sandstones interbedded with glauconitic fine sandstone beds and concretionary horizons. Bivalves, gastropods, and marine reptiles are very common in the molluscan units. These beds represent transgressive shelf deposits followed by a regressive trend in the uppermost part of the López de Bertodano Formation (Olivero, 2012). Molluscan fossils are much less common in the Rotularia Units (which are dominated by fossils of the worm Rotularia) than the Molluscan Units, though they are not absent. Overall, water depth increases from possibly estuarine in the lower units to fully open shelf in the upper units.

\section{Materials and methods}

MLP 87-II-7-1 consists of a left scapula (Fig. 1 A-B) belonging to a juvenile mosasaurs (Plioplatecarpinae, indet) from the López de Bertodano Formation (upper Maastrichtian) of Marambio Island (Seymour Island), Antarctic Peninsula.

Institutional abbreviations. MLP, Museo de La Plata, Buenos Aires Province, Argentina.

\subsection{Paleopathological analysis}

The specimen was analyzed through macroscopic examination and was scanned at the "YPF Tecnología" (Y-TEC) of the company YPF and Consejo Nacional de Investigaciones Científicas y Técnicas (CONICET) in La Plata (Argentina) using an industrial X-ray computed microtomography ( $\mu \mathrm{CT}$, Bruker SkyScan 1773). The material was scanned at $130 \mathrm{kV}, 61 \mu \mathrm{A}$, output file of $1120 \times 1120$ pixels per projection, inter-slice distance of $50 \mu \mathrm{m}$ and voxel size of $40.06 \mu \mathrm{m}$. The X-ray beam was filtered by a $0.25 \mathrm{~mm}$-thick brass filter. A set of 720 projections were acquired by a flat panel detector (Hamamatsu 130/300) over a total scan angle of $360^{\circ}$. The resulting $\mu \mathrm{CT}$ slices were reconstructed using the commercial software NRecon version 1.6.9.8. Reconstructed slices were imported (as stack of BMP 8-bit files) to ImageJ to analyze the microCT images.

\section{Results}

The left scapula is small; its major dorsoventral axis equals $92 \mathrm{~mm}$. The anteroposterior length is $67 \mathrm{~mm}$; the scapular neck to the posterior end, $42 \mathrm{~mm}$. The surface for the articulation with the coracoid is gently convex suggesting that, as in Platecarpus, Plioplatecarpus and Tylosaurus, both elements are not firmly united. The scapular neck is short and its outer edges are thin, lacking the thickened edge for (attachment of cartilage) typical of adults. The region of the scapular blade dorsal to the neck is moderately expanded in lateral aspect (Fig. $1 \mathrm{~A}-\mathrm{B}$ ).

Macroscopic examination of the scapula revealed a remodelled, deeply excavated and expanded gleno-humeral joint with adjacent linear disruption. X-ray examination revealed a deep excavation expanding the glenoid fossa, with disorganized subchondral bone and a focal spherical defect (Fig. 1C-E). There is a depression on the scapular neck in the ventral margin of the left scapula, which is located $2.6 \mathrm{~cm}$ above anterointernal facet articulating with the coracoid. It has a diameter of $0.6 \mathrm{~mm}$ by $0.26 \mathrm{~mm}$ of depth (Fig. 1B-C). The lesion is surrounded by a thin margin of periosteal new bone, elevated of $0.12 \mathrm{~mm}$ above the normal bone surface.

\section{Discussion}

The diagnostic considerations are infectious arthritis and spondyloarthropathy. Both diseases have previously been recognized in mosasaur vertebrae (Rothschild and Martin, 2006; Rothschild et al., 2012a; Rothschild and Everhart, 2015). The former is characterized by erosions with reactive new bone formation (Rothschild and Woods, 1991; Resnick, 2002); the latter, by disorganized trabecular patterns underlying the articular surface (Resnick, 2002; Rothschild and Martin, 2006; Rothschild et al., 2012a). The spheroid defect recognized radiologically and presences of the surface defect (indicative of a draining sinus) are parsimonious with the diagnosis of infectious arthritis. The articulation of the scapula and humerus was disrupted by the glenoid fossa expansion, compromising its normal function as a fulcrum. The limb was thus rendered flail, unable to contribute to propulsion or directionality (steering).

The pathological condition in MLP 87-II-7-1 is infectious. Other possibility for MLP 87-II 7-1 includes trauma to the shoulder region (e.g., predator bite). The individual survived long enough for partial healing, in the form of new bone formation. This process may occur as rapidly as within a few days in mammals, but commonly is more prolonged (e.g., month) in reptiles (Smith and Barker, 1988). However given the high growth rate (e.g. Houssaye et al., 2013) and endothermic metabolism (e.g., Harrell et al., 2016) of hydropelvic mosasaurs, new bone deposition may have occurred much faster than in extant squamates. The individual did not continue to grow 

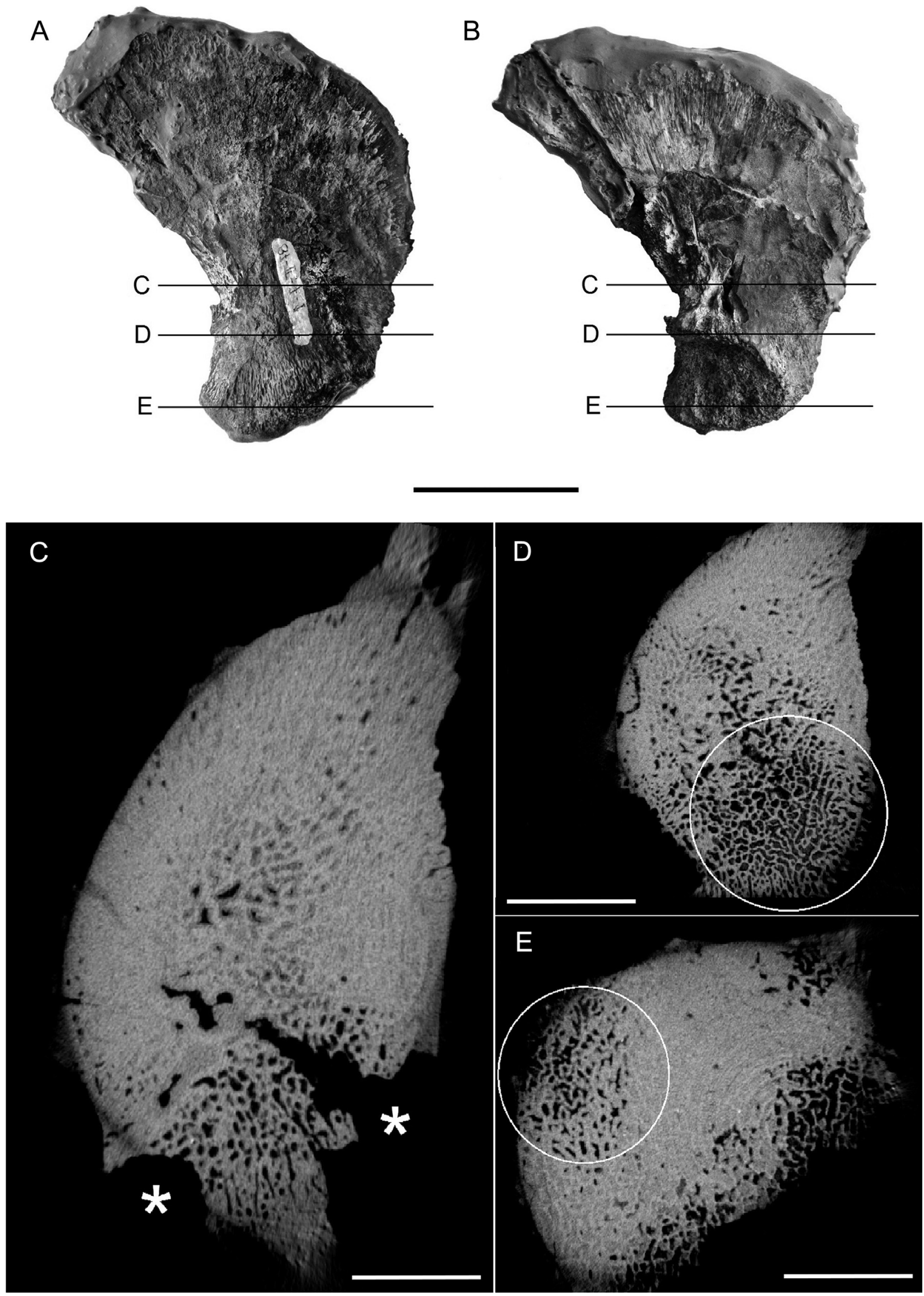

Fig. 1. Left scapula of MLP87-II-7-1 in lateral view (A) and medial view (B). C-E, Microtomography made in different sections show C, draining sinus (asterisk), D-E disorganized trabecular bone. Scale bar: A-B: $4 \mathrm{~cm} ; \mathrm{C}-\mathrm{D}: 1 \mathrm{~cm}$. 
for a long time after the appearance of the lesion. Although not directly related to the mosasaur death, this condition may have contributed to the demise of the animal by reducing its effectiveness at obtaining food or increasing susceptibility to fatal disease, additional injury, or even predation. A juvenile mosasaur with this condition would eventually make it an easy prey.

\section{Conclusions}

We describe infectious arthritis in a scapula of a juvenile mosasaur recovered from the upper Maastrichtian of Antarctica, representing the first report of a paleopathology of a marine reptile from the southern hemisphere. The diagnostic considerations are infectious arthritis and spondyloarthropathy. X-ray examination revealed a deep excavation expanding the glenoid fossa, with disorganized subchondral bone. The articulation of the scapula and humerus was disrupted by the glenoid fossa expansion, compromising its normal function. The individual did not continue to grow for a long time after the appearance of the lesion.

\section{Acknowledgements}

The authors thank IAA (Instituto Antártico Argentino) and Fuerza Aérea Argentina for support in the field. We are also grateful to Erin Maxwell and Judith Pardo-Pérez, who helped improve the manuscript. This research was financially supported by grants from Agencia de Promoción Científica y Tecnológica (ANCyT) (PICT 20161039; PICT 2016-0607), Universidad Nacional de Río Negro PI UNRN 40-A-660 and Programa de Incentivos de la Universidad Nacional de La Plata.

\section{References}

Beatty, B.L., Rothschild, B.M., 2008. Descompression syndrome and the evolution of deep diving physiology in the Cetacea. Naturwissenschaften 95, 793-801.

Bishop, P.J., Walmsley, C.W., Phillips, M.J., Quayle, M.R., Boisvert, C.A., McHenry, C.R., 2015. Oldest pathology in a tetrapod bone illuminates the origin of terrestrial vertebrates. PLoS One 10, e0125723.

Cooper, L.N., Dawson, S.D., 2009. The trouble with flippers: a report on the prevalence of digital anomalies in Cetacea. Zoological Journal of the Linnean Society $155,722-735$.

Elliot, D.H., Askin, R.A., Kyte, F.T., Zinsmeister, W.J., 1994. Iridium and dinocysts at the Cretaceous - Tertiary boundary on Seymour Island, Antarctica: Implications for the K-T event. Geology 22, 675-678.

Harrell Jr., T.L., Pérez-Huerta, A., Suarez, C.A., 2016. Endothermic mosasaurs? Possible thermoregulation of Late Cretaceous mosasaurs (Reptilia, Squamata) indicated by stable oxygen isotopes in fossil bioapatite in comparison with coeval marine fish and pelagic seabirds. Palaeontology 59, 351-363.

Houssaye, A., Lindgren, J., Pellegrini, R., Lee, A.H., Germain, D., Polcyn, M.J., 2013. Microanatomical and Histological Features in the Long Bones of Mosasaurine Mosasaurs (Reptilia, Squamata) - Implications for Aquatic Adaptation and Growth Rates. PLoS One 8 (10), e76741. https://doi.org/10.1371/journal.pone. 0076741.

Kompanje, E., 1999. Considerations on the comparative pathology of the vertebrae in Mysticeti and Odontoceti; evidence for the occurrence of discarthrosis, zygarthrosis, infectious spondylitis and spondyloarthritis. Zoologische Mededelingen 73, 99-130.

Lingham-Soliar, T., 2004. Palaeopathology and injury in the extinct mosasaurs (Lepidosauromorpha, Squamata) and implications for modern reptiles. Lethaia 37, 255-262.

Macellari, C., 1998. Stratigraphy, sedimentology and paleoecology of Upper Cretaceous/Paleocene shelf-deltaic sediments of Seymour Island (Antartic Peninsula). In: Feldmann, R.M., Woodbum, M.O. (Eds.), Geology and Paleontology of Seymour Island, vol. 169. Geological Society of American Memoir, pp. 25-53.

Moodie, R., 1918. Studies in Paleopathology. III. Opisthotonus and Allied Phenomena Among Fossil Vertebrates. The American Naturalist 52, 384-394.

Motani, R., Rothschild, B.M., Wahl, W., 1999. Large eyeballs in diving ichthyosaurs. Nature 402, 747.

O'Gorman, J.P., Talevi, M., Fernández, M., 2017. Osteological ontogenetic changes in aristonectines (plesiosauria; elasmosauridae): insight from a perinatal specimen from Antarctica (López de Bertodano Formation). Antartic Science 29, 61-72. https://doi.org/10.1017/S0954102016000365.

Olivero, E.B., 2012. Sedimentary cycles, ammonite diversity and palaeoenvironmental changes in the Upper Cretaceous Marambio Group, Antarctica. Cretaceous Research 34, 348-366.

Olivero, E.B., Malumián, N., 2008. Mesozoic-Cenozoic stratigraphy of the Fuegian Andes, Argentina. Geologica Acta 1, 5-18.

Pardo Pérez, J.M., Kear, B.P., Gómez, M., Moroni, M., Maxwell, E.E., 2018a. Ichthyosaurian palaeopathology: evidence of injury and disease in fossil 'fish lizards'. Journal of Zoology 304, 21-33.

Pardo-Pérez, J.M., Kear, B., Gómez, M., Moroni, M., Maxwell, E.E., 2018b. Pathological survey on Temnodontosaurus from the Early Jurassic of southern Germany. PLoS One. https://doi.org/10.1371/journal.pone.0204951.

Resnick, D., 2002. Diagnosis of Bone and Joint Disorders. Saunders, Philadelphia.

Rothschild, B.M., Depalma, R., 2013. Skin pathology in the Cretaceous: evidence for probable failed predation in a dinosaur. Cretaceous Research 42, 44-47.

Rothschild, B.M., Everhart, M.J., 2015. Co-ossification of vertebrae in mosasaurs (Squamata, Mosasauridae); Evidence of habitat interactions and susceptibility to bone disease. Transactions of the Kansas Academy of Science 118, 265-275.

Rothschild, B.M., Martin, L., 1987. Avascular necrosis: Occurrence in diving cretaceous mosasaurs. Science 346, 75-77.

Rothschild, B.M., Martin, L.D., 1993. Paleopathology: disease in the fossil record. CRC Press, Boca Raton, Fla.

Rothschild, B.M., Martin, L.D., 2006. Skeletal Impact of Disease. New Mexico Museum of Natural History Press, Albuquerque, New Mexico, 226 p.

Rothschild, B.M., Storrs, W., 2003. Decompression syndrome in plesiosaurs (sauropterygia: reptilia). Journal of Vertebrate Paleontology 23, 324-328.

Rothschild, B.M., Woods, R.J., 1991. Spondyloarthropathy: Erosive arthritis in representative defleshed bones. American Journal of Physical Anthropology 85, 125-134.

Rothschild, B.M., Schultze, H.P., Peligrini, R., 2012a. Herpetological Osteopathology: Annotated Bibliography of Amphibians and Reptiles. Springer, Heidelberg, 450 p.

Rothschild, B.M., Xiaoting, Z., Martin, L.D., 2012b. Adaptations for marine habitat and the effect of Triassic and Jurassic predator pressure on development of decompression syndrome in ichthyosaurs. Naturwissenschaften 299, 443-448.

Rothschild, B.M., Clark Neil, D.L., Clark, C.M., 2018. Evidence for survival in a Middle Jurassic plesiosaur with a humeral pathology: What can we infer of plesiosaur behaviour? Palaeontologia Electronica 1-11. Article 21.1.13.

Smith, D.A., Barker, I.K., 1988. Healing of cutaneous wounds in the common garter snake (Thamnophis sirtalis). Canadian Journal of Veterinary Research = Revue canadienne de recherche veterinaire 52, 111-119.

Tanke, D.H., Rothschild, B.M., 2002. Dinosores: Annotated Bibliography of Dinosaur Paleopathology and Related Topics - 1838-2001. New Mexico Museum of Natural History and Science Bulletin 20, 1-96.

Zinsmeister, W.J., 1998. Discovery of fish mortality horizon at the K-T boundary on Seymour Island: re-evaluation of events at the end of the Cretaceous. Journal of Paleontology 72, 556-571. 